\title{
Doppler ultrasound in pregnancy - quality requirements of DEGUM and clinical application (part 2)
}

\section{Dopplersonografie in der Schwangerschaft - Qualitätsanforderungen der DEGUM und klinischer Einsatz (Teil 2)}

Authors

Renaldo Faber ${ }^{1}$, Kai-Sven Heling ${ }^{2}$, Horst Steiner ${ }^{3}$, Ulrich Gembruch ${ }^{4}$

Affiliations

1 Leipzig, Center of Prenatal Medicine, Leipzig, Germany

2 Praxis, prenetal diagnosis and human genetics, Berlin, Germany

3 Praxis für Pränatalmedizin, Salzburg, Austria

4 Obstetrics and Prenatal Medicine, University Hospital, Bonn, Germany

Key words

dopplersonography, fetal surveillance, guideline, clinical application

received 27.02 .2021

accepted 16.03.2021

published online 27.04.2021

Bibliography

Ultraschall in Med 2021; 42: 541-550

DOI $10.1055 / a-1452-9898$

ISSN 0172-4614

(C) 2021. Thieme. All rights reserved.

Georg Thieme Verlag KG, Rüdigerstraße 14,

70469 Stuttgart, Germany

Correspondence

Prof. Renaldo Faber

Leipzig, Center of Prenatal Medicine, Johannisplatz 1, 04103 Leipzig, Germany

Tel.: $+49 / 341 / 2178075$

Fax: $+49 / 341 / 9939507$

faber@praenatalmedizin-leipzig.de

\section{ABSTRACT}

This second part on Doppler sonography in prenatal medicine and obstetrics reviews its clinical applications. While this has not become the initially anticipated screening tool, it is used for the diagnosis and surveillance of a variety of fetal pathologies. For example, the sonography-based determination of uterine artery blood flow indices is an important parameter for the first trimester multimodal preeclampsia risk assessment, increasing accuracy and providing indication for the prophylactic treatment with aspirin. It also has significant implications for the diagnosis and surveillance of growth-restricted fetuses in the second and third trimesters through Doppler-sonographic analysis of umbilical artery, middle cerebral artery and ductus venosus. Here, especially the hemodynamics of the ductus venosus provides a critical criterium for birth management of severe, early-onset FGR before $34+0$ weeks of gestation. Further, determination of maximum blood flow velocity of the middle cerebral artery is a central parameter in fetal diagnosis of anemia which has been significantly improved by this analysis. However, it is important to note that the mentioned improvements can only be achieved through highest methodological quality. Importantly, all these analyses are also applied to twins and higher order multiples. Here, for the differential diagnosis of specific complications such as TTTS, TAPS and TRAP, the application of Doppler sonography has become indispensable. To conclude, the successful application of Doppler sonography requires both exact methodology and precise pathophysiological interpretation of the data.

\section{ZUSAMMENFASSUNG}

Im 2. Teil zum Einsatz der Methode der Dopplersonografie in der Pränatal- und Geburtsmedizin geht es um den klinischen Einsatz. Die Erwartungen einer breiten Anwendung der Methode als Screeningverfahren haben sich nicht bestätigt. Allerdings spielen die Widerstandsindizes der Aa. uterinae im Rahmen eines multimodalen Ansatzes für die Vorhersage der Präeklampsie im 1. Trimester eine wichtige Rolle, verbessern die Genauigkeit und schaffen die Grundlage für eine effektive Prophylaxe mit Aspirin. Für die Zustandsdiagnostik und Überwachung wachstumsretardierter Föten im 2. und 3. Trimester hat die Dopplersonografie der A. umbilicalis, A. cerebri media und des Ductus venosus eine herausragende Bedeutung. Insbesondere die Hämodynamik des Ductus venosus ist ein entscheidendes Kriterium für das Geburtsmanagement der frühen, schweren IUGR vor 34 SSW. Die maximale Geschwindigkeit in der A. cerebri media ist der zentrale Parameter in der fetalen Anämiediagnostik und hat deren Qualität grundlegend verändert und verbessert. Allerdings sind diese Verbesserungen an eine hohe methodische Qualität der Messung gekoppelt. Dies alles trifft natürlich auch für Zwillinge und höhergradige Mehrlinge zu. Die differenzierte Diagnostik spezifischer Komplikationen von monochorialen Mehrlingen wie FFTS, TAPS und TRAP ist ohne den Einsatz der Dopplersonografie nicht mehr zu denken. Der Erfolg des vielfältigen Einsatzes der Dopplersonografie ist verknüpft mit exakter methodischer Anwendung und präziser pathophysiologischer Interpretation. 


\section{Indications}

The technical principles and quality criteria for performing Doppler sonography in pregnancy have been recently defined [1].

Primary indications for the use of Doppler sonography are listed in the Maternity Guidelines ( $\triangleright$ Table 1 ). In addition, there are now further indications that are contained in the present recommendations ( $\triangleright$ Table 2).

\section{Screening}

Numerous studies in the 2 nd and 3 rd trimesters have demonstrated that increased uterine artery indices ( $\triangleright$ Fig. $\mathbf{1 a}, \mathbf{b}$ ) are associated with more frequent occurrence of preeclampsia, fetal growth restriction (FGR), premature placental abruption, stillbirth, etc. [2-4]. Measurement of the uterine arteries in "lowrisk" cohorts between $18^{+0}$ and $24^{+0}$ gestational weeks resulted in sensitivities of $40-60 \%$ with a false-positive rate around $10 \%$. However, the positive predictive values of $25 \%$ for predicting FGR and/or preeclampsia were very low [5]. Nevertheless, the method is suitable for exclusion diagnostics due to the negative predictive value of 97-99\%. If the Doppler of the uterine artery is unremarkable, the risk of developing severe preeclampsia is very low, and further management of the pregnancy can be modified accordingly [6].

In "high-risk" cohorts, the results were better (sensitivity 70$80 \%$, PPV $50 \%$ ) [7]. However, no effect on perinatological outcome could be demonstrated [8].

At the time of first trimester screening $\left(11^{+0}-14^{+0}\right.$ gestational weeks), the accuracy of predicting preeclampsia by Doppler ultrasonography of the uterine arteries alone is low; detection is 30$40 \%$ with an FPR of $10 \%$. When using a multimodal algorithm (Fetal Medicine Foundation, London) that incorporates other anamnestic, biophysical (e. g., maternal BMI and blood pressure), and biochemical (e. g., PIGF, PAPP-A) parameters, the accuracy of predicting early preeclampsia $\left(<34^{+0}\right.$ gestational weeks) improves tremendously; detection rate 90-95\%, FPR $10 \%$ [9-12]. This form of PE screening in first trimester screening is clinically relevant because prophylactic administration of ASA before $16^{+0}$ gestational weeks can significantly reduce the occurrence and severity of early preeclampsia [13]. Depending on the aspirin dose, the incidence of severe PE can be reduced to one-quarter, and the total number of PE can be reduced to one-half on average [14, 15]. The recommended dose is $150 \mathrm{mg}$ ASA per day in the evening [15].

The technique of measuring the uterine arteries in the $1^{\text {st }}$ trimester ( $\triangleright$ Fig. 2a, b) differs compared with the $2^{\text {nd }}$ and $3{ }^{\text {rd }}$ trimesters and should meet certain quality criteria [16]. In particular, the measurement must be taken close to the cervix in the main branch of the uterine artery. Pulsatility at this time is significantly higher than in the $2^{\text {nd }}$ trimester, and in the majority of pregnancies notching is still detectable, so this alone is not pathologically significant [17].

Transferring the multimodal screening concept to the $2^{\text {nd }}$ and $3^{\text {rd }}$ trimesters also achieves a high detection rate of $85 \%$ with a false-positive rate of $10 \%$ for early preeclampsia [18]. However, it
- Table 1 Indications for the use of Doppler sonography according to the Maternity Guidelines.

suspicion of fetal growth restriction (FGR), pregnancy-induced hypertension, preeclampsia

status post FGR or IUFT

status post preeclampsia/eclampsia

abnormalities of the fetal heart rate (CTG)

suspicion of malformation/fetal disorder

multiple pregnancy with discordant growth

suspicion of heart defects or fetal arrhythmias

- Table 2 Additional indications for the use of Doppler sonography according to the DEGUM (German Society for Ultrasound in Medicine) recommendations.

pre-existing maternal vascular diseases (hypertension, nephropathy, D. mellitus, auto-immune diseases)

diagnosis and monitoring of fetal growth restriction (FGR)

suspicion of fetal anemia

suspicion of fetal infection

fetal hydrops

monitoring of monochorionic multiple pregnancies (FFTS (TOPS, TAPS), TRAP, sFGR)

diagnosis of pathological umbilical cord insertions and vasa previa

diagnosis of placental disorders (e. g. placenta increta)

should be noted that this means that the preventive effect of ASA treatment is significantly lower and that the screening benefit is the adaptation of the monitoring intervals and the time of delivery.

The umbilical artery ( $\vee$ Fig. $\mathbf{3}$ ) is not suitable for screening for FGR, preeclampsia, or other pathologies [19].

\section{Monitoring of high-risk pregnancies}

The importance of the use of Doppler sonography in obstetrics must ultimately be measured by the prevention of complications and the reduction of perinatal or neonatal morbidity and mortality.

In principle, a distinction must be made between pregnancies with pathological Doppler values without vs. with clinical fetal (FGR) and/or maternal symptoms (preeclampsia). Pathological uterine Doppler findings ( $\triangleright$ Fig. 1, 2) are almost always measurable long before the development of clinical symptoms (early warning effect), while pathological fetal Doppler findings ( $\triangleright$ Fig.3) are practically always detectable shortly before or with the onset of complications (e. g., FGR).

If it is already assumed that measurement of the uterine arteries is becoming increasingly important, especially in the context of first trimester screening for risk assessment of various complications, the question arises whether monitoring of pathological findings are useful in the further course of pregnancy. There is 


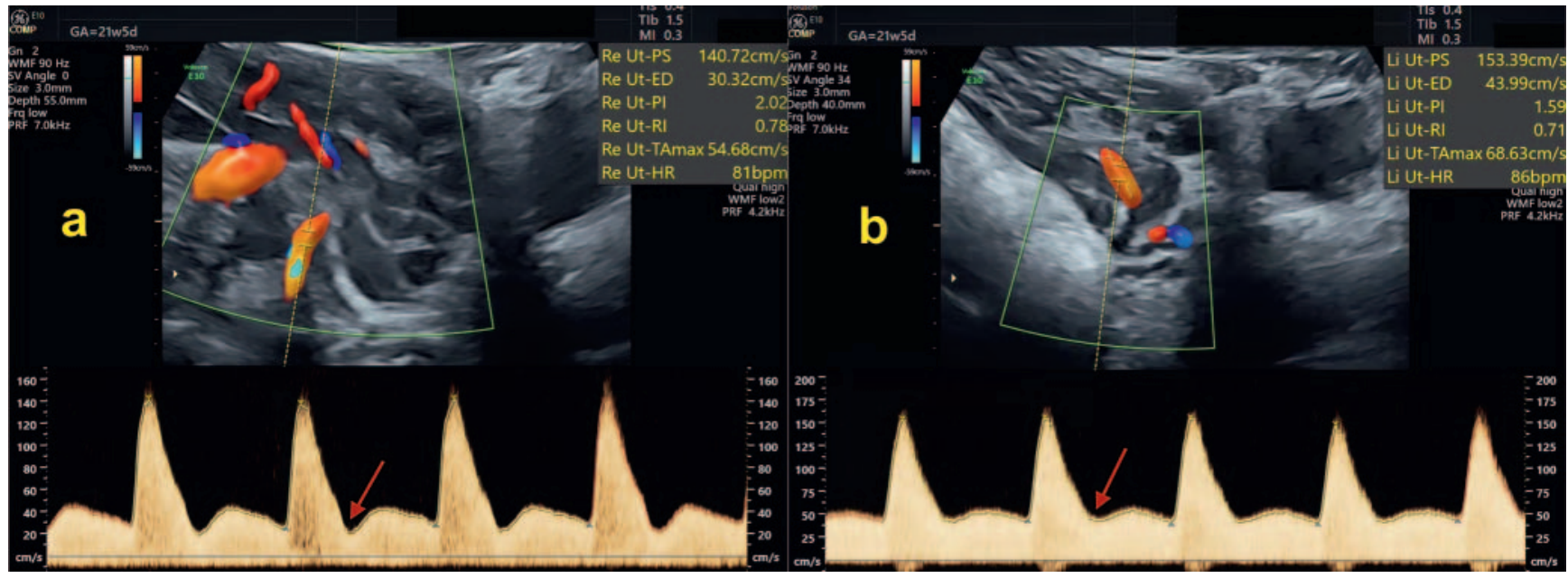

- Fig. 1 Spectral Doppler of the right $\mathbf{a}$ and left $\mathbf{b}$ uterine arteries at $21+5$ gestational weeks with low end-diastolic flow and notching (arrow).

The mean pulsatility index from both uterine arteries is $>1.40$ and lies above the $90^{\text {th }}$ percentile.

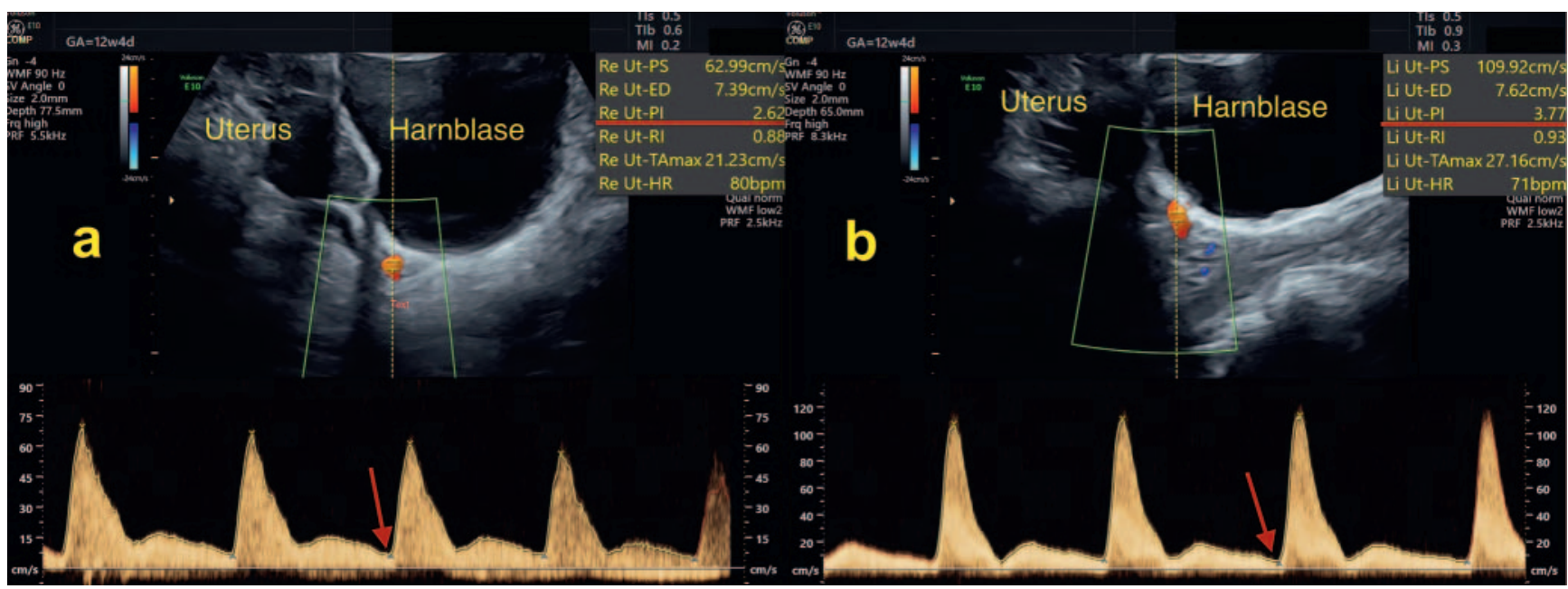

- Fig. 2 Spectral Doppler of the right $\mathbf{a}$ and left $\mathbf{b}$ uterine arteries at $12+4$ weeks measured from abdominal and lateral to the cervix, with very low end-diastolic flow (arrow) and a mean pulsatility index from both uterine arteries $>2.40$, above the $90^{\text {th }}$ percentile.

clear evidence that the adaptation of uterine perfusion to the needs of pregnancy continues well beyond the 1st half of pregnancy $[17,20]$. That is, pathological findings in first trimester screening ( $\bullet$ Fig. 2) may normalize and formerly normal findings in this screening may become pathological. Since this has prognostic significance for the individual pregnancy [17], we recommend monitoring uterine perfusion between $20^{+0}$ and $24^{+0}$ weeks.

In case of persistence of pathological uterine Doppler findings according to a "Uterine Artery Score" (UAS; PI of both uterine arteries $>1.4$ or 1.2 or notch) [21], a check-up between $26^{+0}$ and $28^{+0}$ weeks (biometry, Doppler, placenta) is recommended to detect early-onset deterioration of fetal hemodynamics in a timely manner $[21,22]$. The perinatal risk profile increases significantly if more than 2 of the above parameters (Uterine Artery Score = UAS) are pathological in the sum of both sides [23]. At a UAS of 4, weekly clinical and Doppler sonographic checks are recommended. In this case, supplemental serum screening by sFlt-1/PIGF ratio is also discussed, but generally accepted management protocols are still pending [24].

Employment of fetal Doppler sonography usually begins with the onset of complications to assess fetal status. This can be as early as the first trimester (e. g., ductus venosus in FFTS in multiples), but usually becomes necessary after $20^{+0}$ weeks (FGR, PE, anomaly, anemia).

The most important vessel is the umbilical artery (UA), for which there is clear evidence regarding its benefit for perinatal outcome [25]. It is the first vessel in the temporal cascade to assess fetal status [26], which is complemented by measurement of the middle cerebral artery (MCA) and ductus venosus (DV) when the umbilical artery becomes pathological ( $\triangleright$ Fig. $\mathbf{3}$ ).

In recent years, it has become clear that early severe FGR differs from late FGR in the cascade of Doppler sonographic changes [26-28]. In the early form, as the pathology increases, 


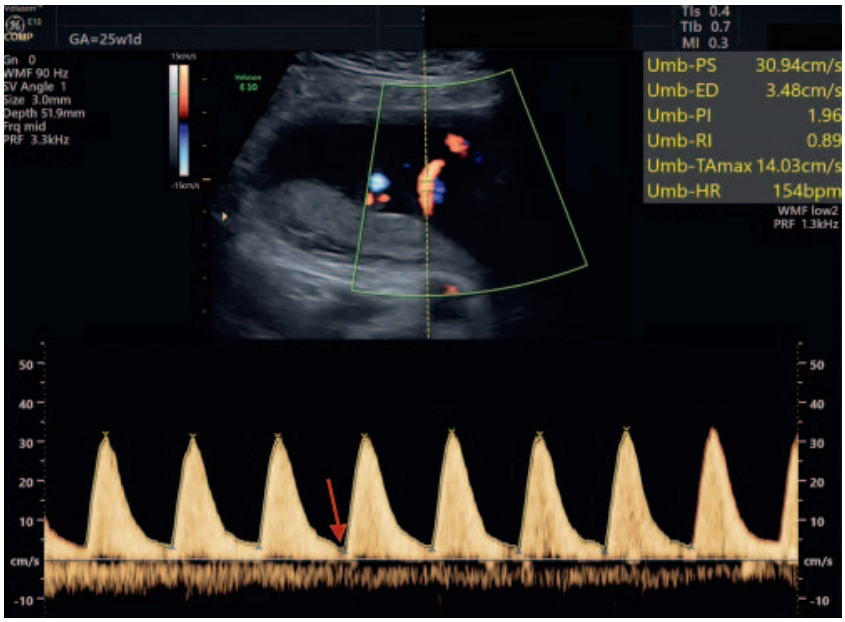

- Fig. 3 Spectral Doppler of the umbilical artery at $25+1$ weeks in pregnancy with FGR, with low end-diastolic flow (arrow) and a pulsatility index $(\mathrm{PI})$ above the $90^{\text {th }}$ percentile.

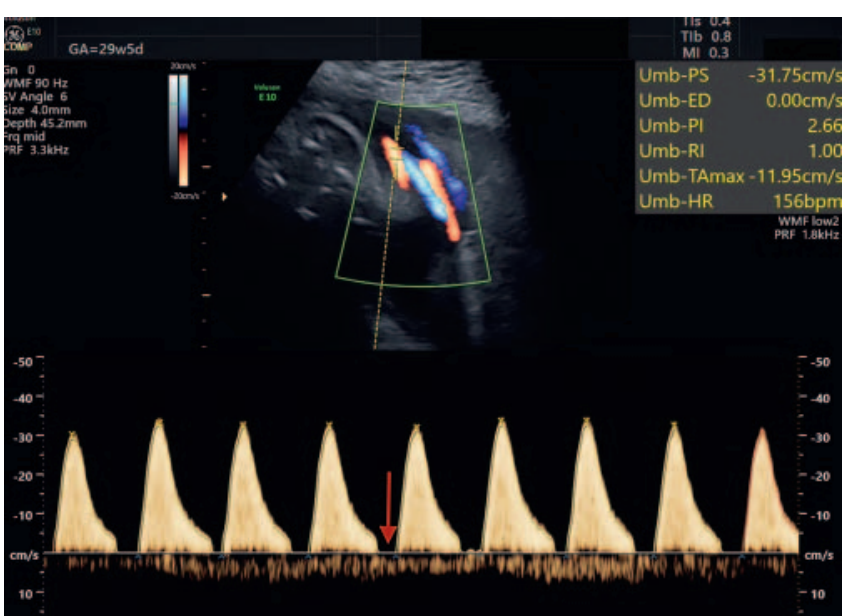

- Fig. 4 Spectral Doppler of the umbilical artery with absent enddiastolic flow (AEDF) (arrow) at $29+5$ weeks of pregnancy with FGR.

Doppler indices in the umbilical artery ( $\bullet$ Fig. 3-5), later in the middle cerebral artery ( $\triangleright$ Fig. $\mathbf{6}$ ), and just before fetal decompensation, those of the venous duct ( $\vee$ Fig. 7) become conspicuous. According to the TRUFFLE study, the decision criterion for delivery before $34^{+0}$ weeks is considered to be negative or reversal of the a-wave in the ductus venosus ( $\triangleright$ Fig. 7) in addition to the STV in the CCTG (short-time variability in computer-supported CTG) [29]. After the appearance of pathological Doppler indices in the umbilical artery ( $\boldsymbol{F} \mathbf{F i g} \mathbf{3}$ ), individualized monitoring begins, which should now be performed by a specialist at shorter intervals after 1-2 weeks. Many different fetal parameters (biometry, amniotic fluid volume, middle cerebral artery, DV, cCTG, biophysical profile, gestational weeks) as well as maternal conditions (history, symptoms) play a modifying role, but in particular the development of the individual Doppler parameters over time (no, slow or rapid deterioration) [26], which also determine the need for inpatient monitoring and the administration of antenatal

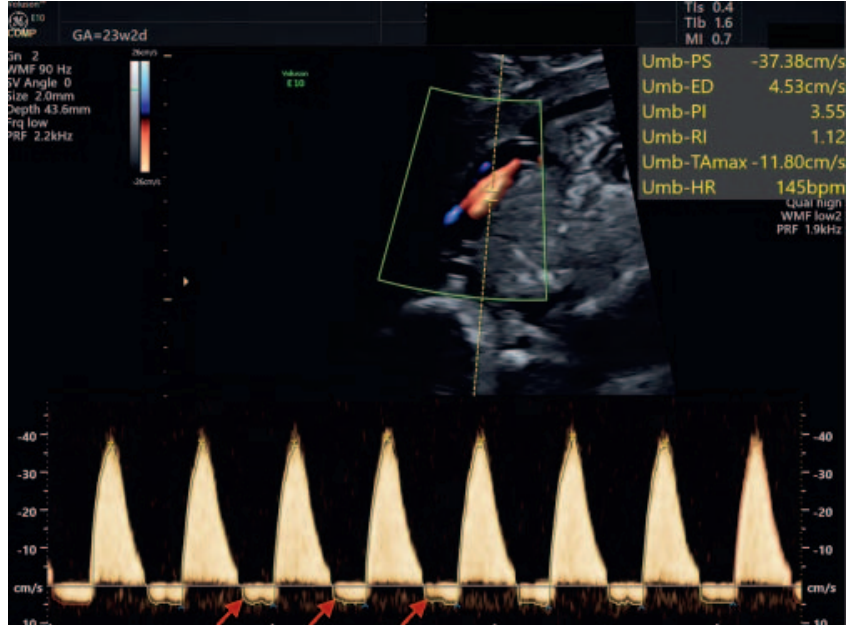

- Fig. 5 Spectral Doppler of the umbilical artery with reversed flow (arrows) at $23+2$ weeks in pregnancy with severe, early FGR.

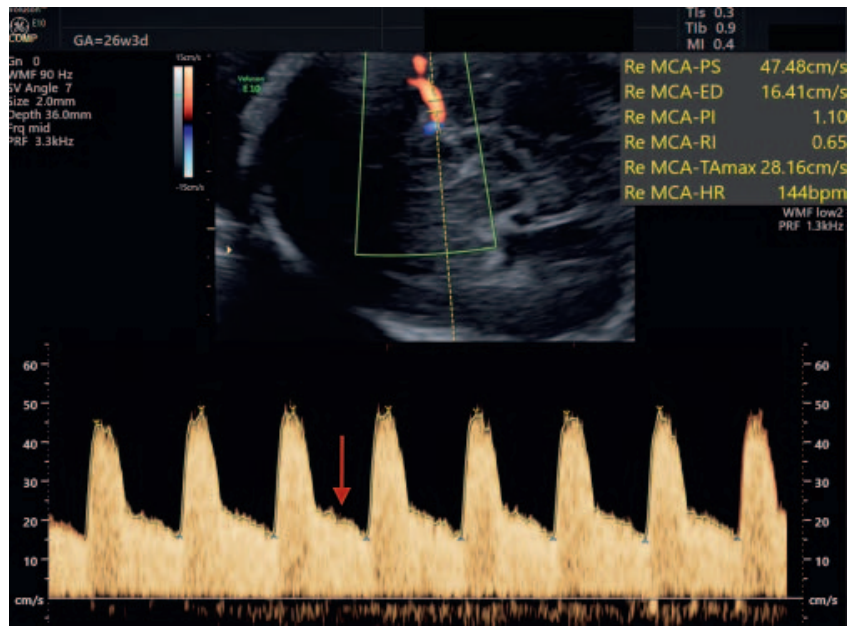

- Fig. 6 Spectral Doppler of the right middle cerebral artery at $26+3$ weeks with high diastolic flow (brain-sparing) (arrow) in pregnancy with FGR and pathological umbilical perfusion.

steroids for lung maturation prophylaxis [30]. Using a cerebroplacental ratio (CPR) could further improve the prediction of the outcome of perinatal disorders [31].

With the more common late fetal growth discrepancy in the third trimester, a distinction must be made between SGA (small for gestational-age) and true FGR (fetal growth restriction). This is only possible with multimodal approaches in which Doppler findings play an important role [31, 32].

In this late period, the end of adaptive mechanisms is reached with fetal circulatory centralization in the middle cerebral artery, which is best documented by the cerebro-placental ratio (CPR) $[31,33,34]$. Prediction of perinatal outcome disorders by CPR is good for individual parameters in FGR [31], perhaps successful multimodally in SGA fetuses [31, 35], and inadequate in unselected pregnancies [36, 37]. This could perhaps also be related to methodological problems and a lack of quality criteria for measur- 


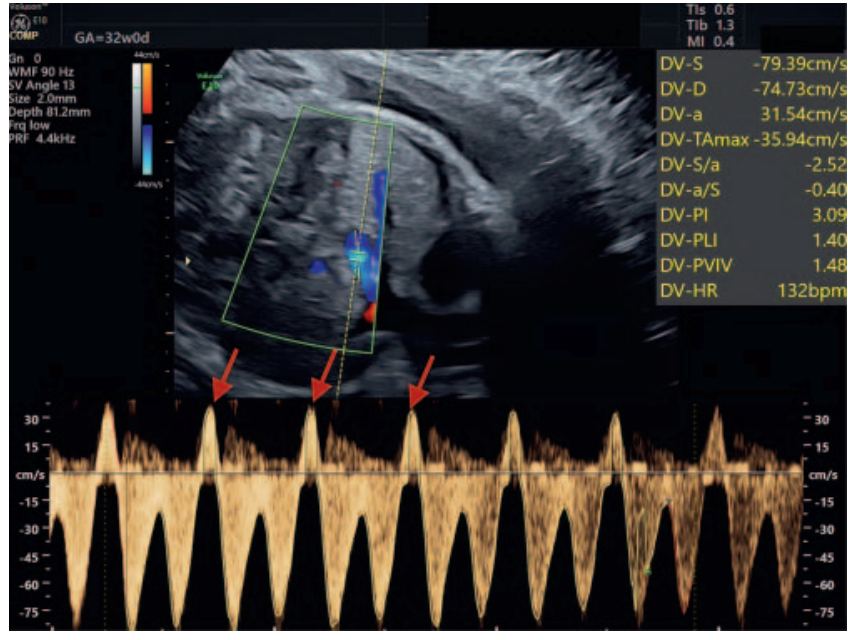

- Fig. 7 Spectral Doppler of the ductus venosus with negative a-wave (reversed-flow) (arrows) at $32+0$ weeks in pregnancy with severe FGR, AEDF in the UA, brain-sparing in the MCA, immediately before elective Cesarean section.

ing CPR to date [38]. The umbilical artery and venous duct may also show elevated indices, but are usually not highly pathological (e. g., zero flow, reverse flow) [30, 34].

\section{Doppler sonography in fetal anemia}

Direct and definitive diagnosis of fetal anemia is made by cordocentesis, an invasive procedure that results in fetal loss due to the procedure in $1 \%$ of cases, depending on gestational age. Doppler sonographic detection of elevated peak systolic velocity (PSV) in the middle cerebral artery is currently the best method to noninvasively diagnose fetal anemia and to serially monitor the fetus if the risk is appropriate ( Fig. 8) [39]. In anemia, there is an increase in blood flow rates in all fetal vessels - arteries and veins as a result of increased cardiac output and decrease in blood viscosity. Primarily for technical reasons, peak systolic velocities (PSV) in the MCA are best suited to detect the presence and extent of anemia, regardless of its etiology. The decrease in hemoglobin and $\mathrm{pCO}_{2}$ correlate with MCA-PSV, but not the $\mathrm{pO}_{2}$ [40]; fetal anemia is not a hypoxemia-triggered blood redistribution, because $\mathrm{pO}_{2}, \mathrm{pCO}_{2}$ and $\mathrm{pH}$ are normal, as are the Doppler indices (PI, RI) or the Doppler spectrum in the arterial and venous vessels.

At this point, it should be mentioned with respect to differential diagnosis that even with severe and early onset of fetal growth restriction, not only is the pulsatility in the middle cerebral artery reduced, but PSV can also be raised [41]. In late pregnancy, fetal hypercapnia may occur in the setting of progressive placental insufficiency with prolongation of the villous diffusion distance, which may also lead to flow acceleration in the middle cerebral artery [40]. In this case, the diagnostic value is therefore limited.

Other less sensitive signs of fetal anemia may include: cardiomegaly with biventricular dilatation, hepatomegaly, splenomegaly, increased echogenicity of the bowel, polyhydramnios, placentomegaly, and hydrops fetalis [42, 43].

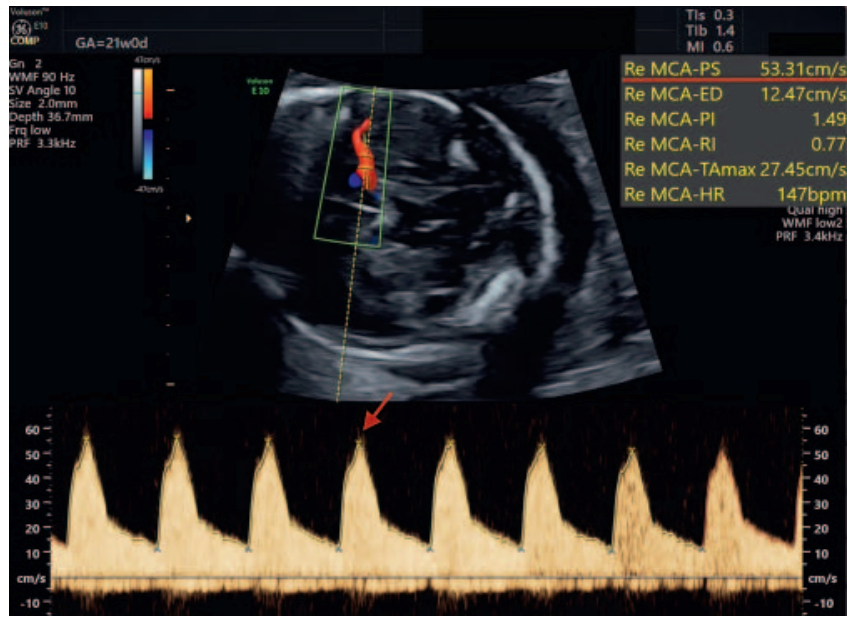

- Fig. 8 Spectral Doppler of the middle cerebral artery at $21+0$ weeks with very high maximum systolic velocity (arrow) in pregnancy with proven PV-B19 infection and fetal anemia.

Fetal anemia is present when hemoglobin concentration and/or hematocrit are below two standard deviations of the gestational age-related reference range. Since both increase with increasing gestational age (mean fetal hemoglobin concentration is $10.6 \mathrm{~g} / \mathrm{dL}$ at $18^{+0}$ gestational weeks, $12.0 \mathrm{~g} / \mathrm{dL}$ at $24^{+0}$ weeks, $12.8 \mathrm{~g} / \mathrm{dL}$ at $30^{+0}$ weeks, and $13.8 \mathrm{~g} / \mathrm{dL}$ at $40^{+0}$ weeks) [39], hemoglobin concentration is calculated as the multiple of median (MoM) relative to gestational age, so that the extent of anemia can be specified independently of gestational age (mild anemia: MoM 0.83-0.65; moderate anemia: MoM: 0.64-0.55; severe anemia: MoM <0.55) [39].

Since MCA-PSV increases during pregnancy from $20-30 \mathrm{~cm} / \mathrm{s}$ at the end of the first trimester to $50-70 \mathrm{~cm} / \mathrm{s}$ in the third trimester, the PSV $(\mathrm{cm} / \mathrm{s})$ is also converted to MoM to express the extent of deviation of PSV from the mean value independent of gestational age [39].

To realize the diagnostic potential of Doppler sonography of MCA-PSV, the measurement must be performed extremely carefully and accurately by an experienced examiner as described in detail in the section on the method [1].

\section{Immunologically induced fetal anemia}

In a prospective study of 111 pregnancies with Rh incompatibility, the sensitivity with respect to moderate and severe fetal anemia was $100 \%$ and the false-positive rate was $12 \%$ when the MCAPSV exceeded the cutoff of 1.5 MoM [39], thus reducing invasive procedures by about $70 \%$ (serial amniocentesis) that would otherwise be required. The choice of intervals between measurements depends on the respective measured velocities in the case of blood group incompatibility [39]. After $35^{+0}$ gestational weeks, the proportion of false-positive results increases. Other studies showed slightly worse results [44, 45].

In case of blood group incompatibility confirmed by detection of maternal alloimmune antibodies (critical titer usually $\geqq 1: 16$, in case of Kell incompatibility $\geqq 1: 8$ ), paternal zygosity is determined 
first; if necessary, direct genotyping of the fetus from amniotic fluid or from free fetal DNA in maternal blood [46] or from amniotic fluid is subsequently performed. If the fetus has the appropriate antigen, fetal monitoring by serial measurements of MCA-PSV starts at $16^{+0}-20^{+0}$ weeks and is then performed every $1-2$ weeks, or at shorter intervals in the case of borderline findings and/or other indications $[47,48]$.

To determine the timing of repeat intrauterine blood transfusion, velocity measurement in the middle cerebral artery is also suitable, but with limitations. Due to the smaller size and viscosity of the previously transfused adult erythrocytes, the MCA-PSV is higher for the same hemoglobin concentration than for fetuses that have not yet been transfused; the optimal borderline after a transfusion was 1.69 MoM, not 1.5 MoM [49]. Because of the mixture of fetal and adult erythrocytes, velocity measurements in the MCA alone are not adequate to fully estimate the extent of anemia, and a daily hemoglobin drop of $0.3 \mathrm{~g} / \mathrm{dL}$ should be assumed for timing further transfusions [49-51].

The key advantages of measuring PSV are noninvasive serial monitoring and avoidance of amniocentesis or cordocentesis. Furthermore, early detection of fetal anemia with subsequent therapy prevents the occurrence of fetal hydrops. The number of transfusions required cannot be reduced [51, 52].

\section{Non-immunologically-induced fetal anemia}

Measurement of MCA-PSV is also applicable in fetal anemias of other causes ( $\vee$ Table 3 ), and in almost all hemolytic and nonhemolytic anemias, such as parvovirus B19, Kasabach-Merritt sequence, fetomaternal transfusion, and TAPS. An exception regarding the strict inverse correlation between MCA-PSV and fetal $\mathrm{Hb}$ is fetal $\alpha$-thalassemia $[53,54]$. In this case, the method of choice is the measurement of the cardiothoracic ratio (CTR). Even in the first trimester, a CTR $>0.5$ is the best diagnostic parameter (sensitivity $97 \%$ with a false-positive rate of $9 \%$ [54].

In the case of sonographic evidence of non-immunological fetal hydrops, measurement of MCA-PSV allows simple, rapid, and reliable detection or exclusion of anemia, in the presence of which intrauterine blood transfusion can immediately improve the condition of these usually severely anemic fetuses.

\section{Parvovirus B19 infection}

The first and early $2^{\text {nd }}$ trimesters appear to be the critical period of fetal parvovirus B19 infection. Transplacental transmission of the virus to the fetus results in consecutive apoptosis of erythroid progenitor cells and transient aplastic anemia. Placentitis, hepatitis, and myocarditis may develop with generalized infection [55, 56]. Myocarditis appears to be responsible for more frequent signs of cardiac dysfunction in contrast to fetuses with blood group incompatibility.

Severe anemia is developed almost exclusively in fetuses almost exclusively during the first and second trimesters; this can lead to fetal hydrops in about $5-10 \%$ and death of the fetus in about 3-5\% around 2-6 weeks after infection; severe fetal anemia occurs less frequently in infections after $16^{+0}$ weeks of gestation $[55,56]$.
- Table 3 Causes of fetal anemia.

aplastic anemia

- Blackfan-Diamond, Fanconi

- Parvovirus B19

- transitory myeloproliferative disorder (TMD)

hemolytic anemia

- Alloimmunization (Rh-, Kell incompatibility, etc.)

- $\alpha$-Thalassemia

- erythrocyte membrane defects

- G6PD deficiency

- Kasabach-Merritt sequence

- cytomegaly

- syphilis

bleeding anemia

- feto-maternal transfusion (FMT)

- hemorrhage (sacrococcygeal teratoma, intestinal perforation)

- fetal vessel damage

- hemorrhage after death of monochorionic twin

- blood shift as a consequence of TAPS

If maternal PV B19 infection is detected, regular Doppler sonographic measurements of MCA-PSV up to 12 weeks after the time of maternal infection are recommended [56, 57].

Highly-elevated PSV is found in PV B19-induced fetal anemia in the first and early second trimesters ( $\triangleright$ Fig. 8). This may be associated with thickened nuchal translucency, cardiomegaly, skin edema ("space suit" phenomenon), polyhydramnios, placentomegaly, and hyperreflective bowel [43]. Since intrauterine transfusions before $20^{+0}$ gestational weeks are difficult and have a higher rate of complications, it seems reasonable to perform intrauterine transfusion not as soon as MCA-PSV is elevated, but only when there are discrete signs of hydrops $[42,43]$.

\section{Feto-maternal transfusion}

The majority of feto-maternal transfusions with subsequent fetal anemia occur in the third trimester, rarely result in hydrops, but may end up as IUFT. Decreased fetal movements and pathologic fetal heart rate tracings on CTG are an indication of this. Causes may include placental disorders, in combination with fetal growth restriction and preeclampsia, as well as maternal abdominal trauma or external turning. Anemia due to feto-maternal transfusion should be rapidly detected or excluded by Doppler ultrasonography of the middle cerebral artery in all of these constellations $[58,59]$.

\section{Other fetal anemias}

Other uncommon fetal anemias also result in increased flow velocities in the middle cerebral artery ( $\triangleright$ Table 3 ). Extremely rare aplastic and hemolytic anemias requiring transfusion in the fetal 
period occur in Blackfan-Diamond syndrome, erythrocyte membrane defects, glucose 6-phosphate dehydrogenase deficiency, type VII mucopolysaccharidosis, or congenital dyserythropoietic anemia (CDA I and II). Not quite as rare are anemias in the context of Kasabach-Merritt sequence in chorangiomas, hepatic hemangiomas, or diffuse hemangiomatosis, as well as in coccygeal teratomas. Fetal cytomegaly infection or syphilis are not infrequently associated with anemia and thrombocytopenia of the fetus, although the anemia is rather mild or moderate, even if fetal hydrops is present. Limited to fetuses with trisomy 21 , transient myelopoiesis (transient myeloproliferative disorder, TMD) may be responsible for fetal anemia [60]. Finally, in a few cases of in utero anemia requiring transfusion, the cause is not found antenatally or postnatally [58].

For an accurate diagnosis of rare fetal anemia, it is critical that extensive blood tests be performed at the time of the first fetal blood draw to narrow down the cause of the anemia. This is hardly possible in already transfused fetuses; the same applies to the detection of fetal HbF cells in maternal blood in case of feto-maternal transfusion [58].

\section{Doppler sonography for twin pregnancies}

Doppler sonography of the fetal vessels is a key monitoring modality in the care of multiple pregnancies. Staging and management are largely determined by Doppler findings. Determination of chorionicity in the first trimester is essential for counseling and differentiated further care [61]. Doppler sonography of the uterine arteries is of secondary importance in multiples [62].

In dichorionic pregnancies, Doppler sonography is essentially used analogously to singleton pregnancies. Here, the more frequent incidence of complications to be monitored, such as FGR and $\mathrm{PE}$, should be noted, also the use in the case of anomalies.

The exceptions arise in complications of monochorionic multiple pregnancies. Classic twin transfusion syndrome (feto-fetal transfusion syndrome, FFTS) is caused by vascular anastomoses between the placental portions of the multiples [63]. Sonographically, the donor twin has oligohydramnios up to a "stuck twin" and a slightly filled to empty bladder, while the recipient twin has polyhydramnios and a full urinary bladder. Further staging includes Doppler criteria that reflect the hemodynamic changes in the fetus [64]. The donor typically shows an increase in pulsatility in the umbilical artery, while the recipient has a cardiac load due to the increase in volume in the form of an increase in pulsatility in the ductus venosus up to a negative or reverse a-wave and pulsations in the umbilical vein. The gold standard of treatment for FFTS is laser coagulation of the anastomoses at the placental surface [65]. Even after such procedures, regular sonographic or Doppler sonographic checks of the umbilical artery, ductus venosus and middle cerebral artery are required to monitor fetal growth or cardiac function.

Twin-anemia-polycythemia sequence (TAPS) is another complication of monochorionic multiple pregnancies. In this case, major $\mathrm{Hb}$ differences occur between the two fetuses via minute $(<1 \mathrm{~mm})$ arterio-venous anastomoses, with anemia of the donor and polycythemia of the recipient [66]. It is notable that further symptoms of classical FFTS are almost never detectable. TAPS appears to occur spontaneously in 3-5\% of monochorionic twins, mostly in the second half of pregnancy, however in $12-16 \%$ of twins with TOPS (twin-oligohydramnion-polyhydramnion-sequence) after laser coagulation, but reduced by the Solomon technique with dichorionization of the placentas $[67,68]$. The diagnosis of TAPS can be easily made by the Doppler sonographic measurement of the MCA-PSV; PSV > 1.5 MoM for anemia of the donor (sensitivity $94 \%$, specificity $74 \%$ ); PSV $<1.0$ MoM for the polycythemia of the recipient (sensitivity $97 \%$, specificity $96 \%$ ) [69]; a delta MCA-PSV >0.5 MoM [70] or $>0.373$ [71] between the two fetuses can be an indication of TAPS even with normal PSV and correlates with the hemoglobin difference.

A rare TRAP sequence (twin-reversed-arterial-perfusion) is diagnosed in addition to the morphological changes of a multiple (acardius, acranius) by Doppler sonography on the basis of the typical flow reversal in the umbilical artery. In this case, flow reversal occurs early in pregnancy via an arterio-arterial anastomosis and ultimately leads to cardiac arrest in the transfused twin [72]. The cardiac stress of the pumping twin should be monitored by Doppler sonography in the venous compartment.

According to the German guideline for monitoring and care of twins [73], selective fetal growth restriction (sFGR) is present regardless of chorionicity if a multiple shows an estimated weight $<3$ rd percentile.

For dichorionic twins at least 2 of the 3 following parameters must be met for sFGR: estimated weight of one multiple $<10$ th percentile, weight difference of both multiples $>25 \%$ or umbilical artery PI of the smaller multiple $>95$ th percentile.

For monochorionic multiples, at least 2 of 4 parameters must be met: estimated weight of one multiple $<10$ th percentile, weight difference of both multiples $>25 \%$ or umbilical artery PI of the smaller multiple $>95$ th percentile [73]. In contrast to dichorionic multiples, in monochorionic pregnancies, sFGR is classified into three types, with Doppler findings being crucial [74].

Type 1 with consistently positive end-diastolic flow in the umbilical artery has the most favorable prognosis. Type 2 with end-diastolic zero flow or negative flow (AREDF) throughout the umbilical artery is associated with a high risk of morbidity and mortality, as expected. Most challenging is the monitoring and management of Type 3 with intermittent cyclic AREDF in the umbilical artery, alternating with normal flow patterns due to arterio-arterial anastomoses. Here, the flow rate in the umbilical Doppler sonogram must be set to slow to record sufficient cycles to monitor the flow pattern over an extended period of time. Type 3 is at high risk of sudden IUFT or neurological damage.

\section{Anemia of the surviving twin}

After death of a monochorionic twin, spontaneously or after selective fetocide, related anemia of the surviving fetus not infrequently occurs in a few hours to days. This effect is caused by a more or less rapid and large blood loss into the placental vascular bed, rarely also into the other twin [75]. This complication can be detected by close-meshed assessment of MCA-PSV and cardiac contractility and filling, initially every hour immediately after the 
procedure, so that an intrauterine blood transfusion can be given on an emergency basis.

\section{Summary}

Doppler sonography of the maternal, uterine and fetal vessels is a method that is now widely used in prenatal and obstetric medicine. The great advantage lies in the fact that the method is noninvasive and can be used repeatedly if employed correctly.

Doppler sonography of the uterine and fetal vessels alone is not a suitable single procedure for screening. However, incorporated into multimodal algorithms, Doppler findings of uterine arteries are an important pillar of prediction accuracy. In particular, screening for early PE in the first trimester has high accuracy. This is all the more significant because ASA provides an effective prophylaxis for PE.

The Doppler findings of the fetal arteries play a major role in the diagnosis of the condition and monitoring of high-risk pregnancies. The changes in the Doppler findings in the UA, MCA and venous duct in their chronological order are important for monitoring the early FGR. The venous duct can be used to optimize the birth management of the fetuses with FGR. The cerebro-placental ratio (CPR) appears to be the most suitable for predicting and monitoring late FGR; a final assessment is still pending, however.

The measurement of the maximum systolic velocity in the middle cerebral artery is of significant importance for the diagnosis of fetal anemia. Thus, former invasive diagnostics with a high complication rate could be replaced by a non-invasive method. Both the indication and the monitoring of fetuses requiring transfusions are very successful.

The advantages of using Doppler sonography seem obvious. This has been proven in a large number of studies for various aspects of the child's outcome after a complicated progression. Ultimately, however, the critical question remains whether perinatal, neonatal, or early childhood morbidity or mortality can be improved. So far, this has only been confirmed for the use of the umbilical artery in high-risk pregnancies.

The clinical utility of Doppler sonographic findings depends crucially on the quality of the examination. It is therefore essential that the specified quality criteria are applied in every examination. Accurate methodological application coupled with correct physiological or pathophysiological interpretation ensure the success of the use of Doppler sonography. Parts 1 and 2 of this "Best Practice Guideline for Doppler Sonography” are intended to provide the foundation for this.

\section{Conflict of Interest}

The authors declare that they have no conflict of interest.

\section{References}

[1] Faber R, Heling KS, Steiner $\mathrm{H}$ et al. Dopplersonografie in der Schwangerschaft - Qualitätsanforderungen der DEGUM und klinischer Einsatz (Teil 1). Ultraschall in Med 2019; 40: 319-325
[2] Harrington K, Cooper D, Lees C et al. Doppler ultrasound of the uterine arteries: the importance of bilateral notching in the prediction of pre-eclampsia, placental abruption or delivery of a small-for-gestationalage baby. Ultrasound Obstet Gynecol 1996; 7: 182-188

[3] Albaiges G, Missfelder-Lobos H, Lees C et al. One-stage screening for pregnancy complications by color Doppler assessment of the uterine arteries at 23 weeks' gestation. Obstet Gynecol 2000; 96: 559-564

[4] Garcia B, Llurba E, Valle L et al. Do knowledge of uterine artery resistance in the second trimester and targeted surveillance improve maternal and perinatal outcome? UTOPIA study: a randomized controlled trial. Ultrasound Obstet Gynecol 2016; 47: 680-689

[5] Papageorghiou A, Yu C, Bindra R et al. Multicenter screening for preeclampsia and fetal growth restriction by transvaginal uterine artery Doppler at 23 weeks of gestation. Ultrasound Obstet Gynecol 2001; 18: 441-449

[6] Pedrosa AC, Matias A. Screening for pre-eclampsia: a systematic review of tests combining uterine artery Doppler with other markers. J Perinat Med 2011; 39: 619-635

[7] Singh T, Leslie K, Bhide A et al. Role of second-trimester uterine artery Doppler in assessing stillbirth risk. Obstet Gynecol 2012; 119: 256-261

[8] Stampalija T, Gyte GLM, Alfirevic Z. Utero-placental Doppler ultrasound for improving pregnancy outcome. Cochrane Database Syst Rev 2010; 2010: CD008363

[9] Bahado-Singh RO, Jodicke C. Uterine Artery Doppler in First-trimester Pregnancy Screening. Clin Obstet Gynecol 2010; 53: 879-887

[10] Akolekar R, Syngelaki A, Poon L et al. Competing risks model in early screening for preeclampsia by biophysical and biochemical markers. Fetal Diagn Ther 2013; 33: 8-15

[11] Poon LC, Nicolaides K. Early Prediction of Preeclampsia. Obstet Gynecol Int 2014; 2014: 297-307

[12] Sotiriadis A, Hernandez-Andrade E, da Silva Costa F et al. ISUOG Practice Guidelines: role of ultrasound in screening for and follow-up of pre-eclampsia. Ultrasound Obstet Gynecol 2018; 53: 7-22

[13] Bujold E, Roberge S, Lacasse Y et al. Prevention of Preeclampsia and Intrauterine Growth Restriction With Aspirin Started in Early Pregnancy. Obstet Gynecol 2010; 116: 402-414

[14] Roberge S, Villa P, Nicolaides K et al. Early administration of low-dose aspirin for the prevention of preterm and term preeclampsia: a systematic review and meta-analysis. Fetal Diagn Ther 2012; 31: 141-146

[15] Rolnik DL, Wright D, Poon LC et al. Aspirin versus Placebo in Pregnancies at High Risk for Preterm Preeclampsia. N Engl J Med 2017; 377: 613-622

[16] Khalil A, Nicolaides K. How to record uterine artery Doppler in the first trimester. Ultrasound Obstet Gynecol 2013; 42: 478-479

[17] Gomez O, Figueras F, Martinez J et al. Sequential changes in uterine artery blood flow pattern between the first and second trimesters of gestation in relation to pregnancy outcome. Ultrasound Obstet Gynecol 2006; 28: 802-808

[18] Gallo DM, Wright D, Casanova C et al. Competing risks model in screening for preeclampsia by maternal factors and biomarkers at 19-24 weeks' gestation. Am J Obstet Gynecol 2016; 214: 619-627

[19] Alfirevic Z, Stampalija T, Gyte GML. Fetal and umbilical Doppler ultrasound in normal pregnancy. Cochrane Database Syst Rev 2015; 2015 : CD001450

[20] Prefumo F, Guven M, Ganapathy R et al. The longitudinal variation in uterine artery blood flow pattern in relation to birth weight. Obstet Gynecol 2004; 103: 764-768

[21] Khalil A, Garcia-Mandujano R, Maiz N et al. Longitudinal changes in uterine artery Doppler and blood pressure and risk of pre-eclampsia. Ultrasound Obstet Gynecol 2014; 43: 541-547

[22] Bakalis S, Stoilov B, Akolekar R et al. Prediction of small-for-gestationalage neonates: screening by uterine artery Doppler and mean arterial pressure at 30-34 weeks. Ultrasound Obstet Gynecol 2015; 45: 707-714 
[23] Li N, Ghosh G, Gudmundsson S. Uterine artery Doppler in high-risk pregnancies at 23-24 gestational weeks is of value in predicting adverse outcome of pregnancy and selecting cases for more intense surveillance. Acta Obstet Gynecol Scand 2014; 93: 1276-1281

[24] Zeisler H, Llurba E, Chantraine F et al. Predictive Value of the sFlt-1:PIGF Ratio in Women with Suspected Preeclampsia. N Engl J Med 2016; 374 : $13-22$

[25] Alfirevic Z, Stampalija T, Gyte G. Fetal and umbilical Doppler ultrasound in high-risk pregnancies. Cochrane Database Syst Rev 2013; 2013: CD007529

[26] Turan OM, Turan S, Gungor S et al. Progression of Doppler abnormalities in intrauterine growth restriction. Ultrasound Obstet Gynecol 2008; 32: 160-167

[27] Baschat AA. Neurodevelopment following fetal growth restriction and its relationship with antepartum parameters of placental dysfunction. Ultrasound Obstet Gynecol 2011; 37: 501-514

[28] Figueras F, Gratacos E. Stage-based approach to the management of fetal growth restriction. Prenat Diagn 2014; 34: 655-659

[29] Lees CC, Marlow N, van Wassenaer-Leemhuis A et al. 2 year neurodevelopmental and intermediate perinatal outcomes in infants with very preterm fetal growth restriction (TRUFFLE): a randomised trial. Lancet 2015; 385: 2162-2172

[30] Kehl S, Dötsch J, Hecher K et al. Intrauterine Growth Restriction. Guideline of the German Society of Gynecology and Obstetrics (S2k-Level, AWMF Registry No. 015/080, October 2016). Geburtshilfe Frauenheilkd 2017; 77: 1157-1173

[31] Conde-Agudelo A, Villar J, Kennedy $\mathrm{H}$ et al. Predictive accuracy of cerebroplacental ratio for adverse perinatal and neurodevelopmental outcomes in suspected fetal growth restriction: systematic review and meta-analysis. Ultrasound Obstet Gynecol 2018; 52: 430-441

[32] Miranda J, Rodriguez-Lopez M, Triunfo S et al. Prediction of fetal growth restriction using estimated fetal weight vs a combined screening model in the third trimester. Ultrasound Obstet Gynecol 2017; 50: 603-611

[33] Baschat AA, Gembruch U. The cerebroplacental Doppler ratio revisited. Ultrasound Obstet Gynecol 2003; 21: 124-127

[34] Oros D, Figueras F, Cruz-Martinez $R$ et al. Longitudinal changes in uterine, umbilical and fetal cerebral Doppler indices in late-onset small-for-gestational age fetuses. Ultrasound Obstet Gynecol 2011; 37: 191-195

[35] Figueras F, Savchev S, Triunfo $S$ et al. An integrated model with classification criteria to predict small-for-gestational-age fetuses at risk of adverse perinatal outcome. Ultrasound Obstet Gynecol 2015; 45: 279-285

[36] Bakalis S, Akolekar R, Gallo DM et al. Umbilical and fetal middle cerebral artery Doppler at 30-34 weeks' gestation in the prediction of adverse perinatal outcome. Ultrasound Obstet Gynecol 2015; 45: 409-420

[37] Akolekar R, Syngelaki A, Gallo DM et al. Umbilical and fetal middle cerebral arteryDoppler at 35-37 weeks' gestation in the prediction of adverse perinatal outcome. Ultrasound Obstet Gynecol 2015; 46: 82-92

[38] Oros D, Ruiz-Martinez S, Staines-Urias E et al. Reference ranges for Doppler indices of umbilical and fetal middle cerebral arteries and cerebroplacental ratio: systematic review. Ultrasound Obstet Gynecol 2019; 53: 454-464

[39] Mari G, Deter RL, Carpenter RL et al. Noninvasive diagnosis by Doppler ultrasonography of fetal anemia due to maternal redcell alloimmunization. Collaborative Group for Doppler Assessment of the Blood Velocity in Anemic Fetuses. N Engl J Med 2000; 342: 9-14

[40] Picklesimer AH, Oepkes D, Moise A et al. Determinants of the middle cerebral artery peak systolic velocity in the human fetus. Am J Obstet Gynecol 2007; 197: 526.e1-526.e4

[41] Mari G, Hanif F, Kruger M et al. Middle cerebral artery peak systolic velocity: a new Doppler parameter in the assessment of growth-restricted fetuses. Ultrasound Obstet Gynecol 2007; 29: 310-316
[42] Kempe A, Rösing B, Berg C et al. First-trimester treatment of fetal anemia secondary to parvovirus B19 infection. Ultrasound Obstet Gynecol 2007; 29: 226-228

[43] Hellmund A, Berg C, Geipel A et al. Early intrauterine transfusion in fetuses with severe anemia caused by parvovirus B19 infection. Fetal Diagn Ther 2018; 43: 129-137

[44] Oepkes D, Seaward PG, Vandenbussche FP et al. DIAMOND Study Group: Doppler ultrasonography versus amniocentesis to predict fetal anemia. N Engl J Med 2006; 355: 156-164

[45] Pretlove SJ, Fox CE, Khan KS et al. Noninvasive methods of detecting fetal anaemia: a systematic review and meta-analysis. BJOG 2009; 116: 1558-1567

[46] Scheffer PG, van der Schoot CE, Page-Christiaens GC et al. Noninvasive fetal blood group genotyping of rhesus D, c, E and of $\mathrm{K}$ in alloimmunised pregnant women: evaluation of a 7-year clinical experience. BJOG 2011; 118: $1340-1348$

[47] Moise KJ Jr, Argoti PS. Management and prevention of red cell alloimmunization in pregnancy: a systematic review. Obstet Gynecol 2012; 120: $1132-1139$

[48] Mari G, Norton ME, Stone J et al. Society of Maternal-Fetal Medicine (SFMF) Clinical Guideline \#8: the fetus at risk for anemia - diagnosis and management. Am J Obstet Gynecol 2015; 212: 697-710

[49] Detti L, Oz U, Guney I et al. Collaborative Group for Doppler Assessment of the Blood Velocity in Anemic Fetuses: Doppler ultrasound velocimetry for timing the second intrauterine transfusion in fetuses with anemia from red cell alloimmunization. Am J Obstet Gynecol 2001; 185: 10481051

[50] Scheier M, Hernandez-Andrade E, Fonseca EB et al. Prediction of severe fetal anemia in red blood cell alloimmunization after previous intrauterine transfusions. Am J Obstet Gynecol 2006; 195: 1550-1556

[51] Dodd JM, Andersen C, Dickinson JE et al. MCA Doppler Study Group. Fetal middle cerebral artery Doppler to time intrauterine transfusion in red-cell alloimmunization: a randomized trial. Ultrasound Obstet Gynecol 2018; 51: 306-312

[52] Garabedian C, Vaast P, Behal $\mathrm{H}$ et al. Management of severe fetal anemia by Doppler measurement of middle cerebral artery: are there other benefits than reducing invasive procedures. Eur J Obstet Gynecol Reprod Biol 2015; 192: 27-30

[53] Lam YH, Tang MH. Middle cerebral artery Doppler study in fetuses with homozygous alpha-thalassaemia-1 at 12-13 weeks of gestation. Prenat Diagn 2002; 22: 56-58

[54] Leung TY, Lao TT. Thalassaemia in pregnancy. Best Pract Res Clin Obstet Gynecol 2012; 26: 37-51

[55] Lamont RF, Sobel JD, Vaisbuch E et al. Parvovirus B19 infection in human pregnancy. BJOG 2011; 118: 175-186

[56] de Jong EP, Lindenburg IT, van Klink JM et al. Intrauterine transfusion for parvovirus B19 infection: long-term neurodevelopmental outcome. Am J Obstet Gynecol 2012; 206: 204.e1-205

[57] Cosmi E, Mari G, Delle Chiaie L et al. Noninvasive diagnosis by Doppler ultrasonography of fetal anemia resulting from parvovirus infection. Am J Obstet Gynecol 2002; 187: 1290-1293

[58] Amann C, Geipel A, Müller A et al. Fetal anemia of unknown cause - a diagnostic challenge. Ultraschall in Med 2011; 32 (Suppl. 2): E115-E121

[59] Wylie B], D’Alton ME. Fetomaternal hemorrhage. Obstet Gynecol 2010; 115: 1039-1051

[60] Tamblyn JA, Norton A, Spurgeon L et al. Prenatal therapy in transient abnormal myelopoiesis: a systematic review. Arch Dis Child Fetal Neonatal Ed 2016; 101: F67-F71

[61] Khalil A, Rodgers M, Baschat A et al. ISUOG Practice Guidelines: role of ultrasound in twin pregnancy. Ultrasound Obstet Gynecol 2016; 47: 247-263 
[62] Geipel A, Berg C, Germer U et al. Doppler assessment of the uterine circulation in the second trimester in twin pregnancies: prediction of pre-eclampsia, fetal growth restriction and birth weight discordance. Ultrasound Obstet Gynecol 2002; 20: 541-545

[63] Fisk NM, Duncombe G], Sullivan M. The basic and clinical science of twin-twin transfusion syndrome. Placenta 2009; 30: 379-390

[64] Quintero RA, Morales W], Allen MH et al. Staging of twin-twin transfusion syndrome. J Perinatol 1999; 19: 550-555

[65] Senat MV, Deprest J, Boulvain M et al. Endoscopic laser surgery versus serial amnioreduction for severe twin-to-twin transfusion syndrome. N Engl J Med 2004; 351: 136-144

[66] Slaghekke F, Kist WJ, Oepkes D et al. Twin anemia-polycythemia sequence: diagnostic criteria, classification, perinatal management and outcome. Fetal Diagn Ther 2010; 27: 181-190

[67] Slaghekke F, Lewi L, Middeldorp JM et al. Residual anastomoses in twin-twin transfusion syndrome after laser: the Solomon randomized trial. Am J Obstet Gynecol 2014; 211: 285.e1-e7

[68] van Winden KR, Quintero RA, Kontopoulos EV et al. Pre-operative twin anemia/polycythemia in the setting of twin-twin transfusion syndrome (TTTS). Fetal Diagn Ther 2015; 37: 274-280

[69] Slaghekke F, Pasman S, Veujoz M et al. Middle cerebral artery peak systolic velocity to predict fetal hemoglobin levels in twin anemiapolycythemia sequence. Ultrasound Obstet Gynecol 2015; 46: 432-436
[70] Tollenaar LSA, Lopriore E, Middeldorp JM et al. Improved antenatal prediction of twin anemia-polycythemia sequence by delta middle cerebral artery peak systolic velocity: a new antenatal classification system. Ultrasound Obstet Gynecol 2019; 53: 788-793

[71] Tavares de Sousa M, Fonseca A, Hecher K. Role of fetal intertwin difference in middle cerebral artery peak systolic velocity in predicting neonatal twin anemia-polycythemia sequence. Ultrasound Obstet Gynecol 2019; 53: 794-797

[72] Lewi L, Valencia C, Gonzales E et al. The outcome of twin reversed arterial perfusion sequence diagnosed in the first trimester. Am J Obstet Gynecol 2010; 203: 213.e1-4

[73] von Kaisenberg CS, Klaritsch P, Ochsenbein-Kölble N et al. AWMF LL 015087 S24. Überwachung und Betreuung von Zwillingsschwangerschaften.

[74] Gratacos E, Lewi L, Munoz B et al. A classification system for selective intrauterine growth restriction in monochorionic pregnancies according to umbilical artery Doppler flow in the smaller twin. Ultrasound Obstet Gynecol 2007; 30: 28-34

[75] Mackie FL, Rigby A, Morris RK et al. Prognosis of the co-twin following spontaneous single intrauterine fetal death in twin pregnancies: a systematic review and meta-analysis. BJOG 2019; 126: 569-578 